\title{
Secondary school pre-service mathematics teachers' content knowledge of algebraic word problem in Nigeria
}

\author{
Ahmed Ibrahim Usman \\ Department of General studies (Mathematics), Jubail University College, Jubail Industrial City, Kingdom of Saudi Arabia \\ For correspondence: usmana@ucj.edu.sa
}

\begin{abstract}
Knowledge and understanding of mathematical operations serves as a pre-requisite for the successful translation of algebraic word problems. This study explored pre-service teachers' ability to recognize mathematical operations as well as use of those capabilities in constructing algebraic expressions, equations, and their solutions. The outcome of the study indicated that pre-service mathematics teachers were unable to identify words/phrases that represent mathematical operations fluently in isolated cases, construct algebraic expression, equations and their solutions from word problems. It was expected that college courses would have profound influence on their performance, but that does not augment positively.

Keywords:algebraic processes, consecutive even/odd numbers, mathematics content knowledge, visualization, word problems
\end{abstract}

\section{Introduction}

High (senior) and middle (junior) secondary school Mathematics teachers in Nigeria are mostly subject specialists. They are either university graduates with a bachelors' degree in mathematics combined with education, or specialize in mathematics alone; a non-degree Nigeria Certificate in Education (NCE, combining mathematics with another subject (mostly sciences (biology, physics, chemistry, and geography), computer science and education). Moreover, there are some who graduated with a national diploma in mathematics combined with education.

Mathematics-content education at a senior/junior secondary school level in Nigeria plays a vital role in setting the phase for developing individuals that contribute towards laying the foundation for national development (economics, sciences, technology, politics, humanities and social sciences, etc). To uplift and achieve optimum level of growth in these subsectors, in 2007, the Nigerian Educational Research and Development Council (NERDC) reviewed the secondary (senior/junior) school Mathematics curriculum to give a more functional mathematics education. In addition to that, it was an attempt to actualize the holistic goals of national policy on education, as well as, most recently, objectives of National Economic Empowerment and Development Strategies (NEEDS) and the Millennium Development Goals (MDG). Delivering sound mathematics education to students would optimize these goals, but such, would not be attainable without well trained and knowledgeable mathematics teachers. It is really very imperative that teachers of mathematics who would undertake these tasks are well qualified and well-informed mathematically, so that they can impart this knowledge proficiently to their students. 
The NERDC reviewed senior/junior secondary school mathematics curriculum is five-pronged, and are: number and numeration, algebraic processes, geometry (plane, solid, coordinate and trigonometry), statistics and introductory calculus. It is expected that pre-service teachers for secondary and junior secondary schools are, by virtue of their training, able to teach these contents of mathematics curriculum fluently. However, there are limited studies that assess mathematics content knowledge of pre-service mathematics teachers in Nigeria. This study is a sequential explanatory mixed methods design to effectively investigate pre-service teachers' content knowledge in algebraic word problems. Algebraic word problems are components of algebraic processes pronged of the new mathematics curriculum for both senior and junior secondary schools. Moreover, concepts related to algebraic word problems also constitute a good portion of national examinations such as WASSCE (West African Senior Secondary Certificate Examination); NECO (National Examination Commission) and UTME (Unified Tertiary Matriculation Examination).

\section{The Study}

\section{Purpose}

Basic knowledge of some key English words that indicate certain mathematical operations is a useful tool for solving algebraic word problems and algebra story problems. The objective of this sequential explanatory mixed methods study in two-phases would be to collect and analyze data quantitatively using descriptive statistics and then follow-up with qualitative analysis using thematic content analysis of the test manuscript, Creswell (2003). The first segment of the study would attend to quantitative research questions by describing and categorizing the performance of the pre-service mathematics teachers' knowledge on key words that represent mathematical operations and how they were applied in the construction of algebraic expressions, algebraic equations and their solutions from word problems. In a similar vein, the qualitative component using content analysis would further explain their characteristics in a more detailed fashion, Onwuegbuzie \& Teddlie (2003. The following Research questions were used for the study:

1(a) Are the pre-service teachers able to identify and classify phrases/words that represent mathematical operations?

1(b) How do the pre-service teachers able to identify and classify select words that represent mathematical operations.

2(a) Are the pre-service teachers able to construct algebraic expressions from word problems?

2(b) How do the pre-service teachers able to construct algebraic expressions from word problems?

3(a) Are the pre-service teachers able to construct equations from word problems?

3(b) How do the pre-service teachers construct equations from word problems?

4(a) Are pre-service teachers able to construct and solve equations from word problems?

4(b) How do the pre-service teachers able to construct and solve equations from wordproblems?

5) How do the qualitative results from the second stage assist in elucidating the quantitative outcome from the first stage?

The (a) parts of the research questions are the quantitative portion, while the (b) parts are the qualitative components. The fifth is a mixed methods research question. 


\section{Related Literature}

\section{Teacher education in Nigeria}

Teaching education as stated by Wikipedia online encyclopaedia "is policies and procedures designed to equip prospective teachers with knowledge, attitudes, behaviors and skills they require to perform their tasks effectively in classroom, school and wider community". Four key words (knowledge, attitude, behavior and skills) comprehensively and exhaustively describe holistically what teacher education is set to accomplish. This stance is further reiterated by Oyekan (2006) as cited Okemakinde, et. al (2013). They claimed that, "the purpose of teacher education is to produce well - qualified professional teachers that can adjust to the changing needs of students and developmental prospects of modern society", (p.967). The question that one may likely ask is, how can we produce a qualified teacher? To achieve this fate, Okemakinde states that, the National Policy on Education (2004), describe the qualities expected of a qualified teacher after receiving training as:

o Produce highly motivated, conscientious and efficient classroom teachers for all levels of our education system

o Encourage further the spirit of enquiry and creativity in teachers

o Help teachers to fit into the social life of the community and society at large and to enhance their commitment of national goals

o Provide teachers with the intellectual and professional background adequate for their assignment and make them adaptable to any changing situation not only in the life of their country, but in the wider world

o Enhance teacher's commitment to teaching profession.

Furthermore, the document stipulated that training should be offered at Colleges of Education, Faculties of Education in Universities and polytechnics, National Teachers Institute, and so on.

Naturally, set goals/objectives in any human endeavour are met with some hurdles in the process of actualizing them. The teacher education program in Nigeria is not an exception. A lot of researchers have documented a plethora of problems that are: historical (Ogunrinade, 2013, Jekayinfa, n.d; Ejima, 2012; Afe, 2006; Osuji, 2009; Oyeleke, Akinyeye, Opeloye, 2013); funding (Okemakinde, Adewuyi, Alabi, 2013; Ejima, 2012; Oyeleke, Akinyeye, Opeloye, 2013; Ibidapo-obe, 2007; Afe, 2006), curriculum content (quality) (Tom-Lawyer, 2014, Ogunrinade, 2013, Ibidapo-obe, 2007, Akinbote, 2007, Okemakinde, Adewuyi, Alabi, 2013 ), regulatory/standardization (Adeosun, n.d; Ejima, 2012, Ibidapo-obe, 2007; Osuji, 2009; Afe, 2006) and so on.

\section{Nigeria Certificate in Education (NCE) Curriculum in Mathematics}

A Nigeria Certificate in Education is a three year, (minimum of six semesters) program mounted by colleges of education (federal and states), under the guide of the National Commission of Colleges of Education to train subject specialists that can teach fluently at primary and junior secondary schools. In many situations, they happened to teach in senior secondary schools because of the acute shortage of mathematics teachers across the country.

According to the National Commission for Colleges of Education (NCCE) Minimum Standard, (2012), the Philosophy of the NCE Mathematics, "desires students to become intellectually informed in mathematical ideas, notations and skills for logical reasoning, scientific enquiry and for the pursuit of techno-scientific education. It also emphasized the needs to produce non-graduates (non university graduates), but well-groomed and qualified professional teachers of mathematics for basic education levels", (p.200). NCE Mathematics curriculum was designed to produce subject specialists in mathematics 
with second subjects (Biology, Chemistry, Physics, Integrated Sciences, Geography and so on). Other course components of NCE Mathematics curriculum are Education (psychology, sociology, philosophy, history of education; curriculum studies and so on), and general studies (language and communication skills, computer literacy, family life and health, mathematics literacy, citizenship education, science and technology in society, entrepreneurship and political economy); teaching practice (practicum) (NCCE minimum standard, 2012).

The objectives of the NCE mathematics program as stated in the NCCE minimum standard, includes, but not limited to the following: trainees should be able to discuss the historical development of mathematics confidently; solve abstract problems through the use of mathematics skills and ideas; teach mathematics that can help enable learners to apply it in solving daily problems; use games and simulations in a friendly way in mathematics classes; and prepare learners for further studies in mathematics and related course.

\section{Teachers' content knowledge}

Teachers' knowledge has been subjected to various forms of tests over the years. According to Hill et al (2007), there are variations in purpose, for example, certification (Angus, 2001; Haney, Madaus, \&Kreitzer, 1987); appraising the content knowledge (Borko, et al., 1992; Ma, 1999; Simon, 1993; Tirosh\&Graeber, 1990). Similarly, another reason put forward for such tests is, assessing the implication of teachers' knowledge on students' performance.

In a summary of four studies on the effectiveness of teachers' knowledge, Walshaw (2012) states that, teachers' conceptual understanding and knowledge is critically important at any level of teaching. He further opines that, "teachers' fragile subject knowledge often puts boundaries around the ways in which they might develop students' understanding. On the other hand, teachers with sound knowledge make good sense of mathematical ideas." This position is further reiterated by Hill \& Ball, (2004), cited by Zerpa, Kajender\& Van Barneveld, (2009). In a contrary opinion, some researchers claim that higher level mathematical ability was not sufficient to teach effectively. They have the belief that, teachers' mathematics content knowledge (concepts, procedures) and pedagogical content knowledge (how to teach content to students), put together are more important (Ma, 1999; Ambrose, 2004; Schommer Aikins, Duell \& Hutter, 2005), cited by Zerpa et al; (Mohr, 2006; Shulman, 1986). A third window of view, different from the ones express above, was professed by other researchers. According to Hiebert, et al (2005) referred by Zerpa et al, (2009), teaching of mathematics constitutes an interrelated system of features. The characteristics of this new approach to teaching of mathematics include, "knowledge and values that teachers and students bring to the lesson, tasks presented in the classroom, teaching strategies, students' discourse and participation, the assessments and the physical materials available for teaching". The establishment and the way these characteristics were used in a classroom setting give way for effectively helping students attain mathematics learning goals.

\section{Pre-service Teachers of Algebra}

Research related to the subject-matter knowledge of the pre-service trainee, as well as the beliefs associated with that knowledge as alluded by Kieren (2007), includes a study by Van Dooren, Verschaffel, and Onghena $(2002,2003)$. According to them, as cited by her, in the pre-service teachers' preferential strategies for solving arithmetic and algebra word problems, they observed that future secondary school mathematics teachers use algebraic methods for solving even very easy problems that could have been handled more appropriately with arithmetic methods. Half of the primary school preservice teachers were found to switch flexibly between arithmetic and algebraic methods, whereas the other half had difficulty with algebraic methods. The authors also noted that the methods teachers used 
as individuals were strongly correlated with what they would expect their future students to use and by which they would evaluate student work. Similar results have been reported by Schmidt and Bednarz (1997). In another study reported by Kieren, conducted by Zazkis and Liljedahl (2002) involving a group of pre-service elementary school teachers, participants' attempts to generalize a repeating visual number pattern led to the verbal expression of the generality without necessarily being accompanied by algebraic notation. However, participants perceived that their solutions that did not involve algebraic symbolism, although complete and accurate, were inadequate.

\section{Algebra (word problem) learning difficulties}

Generating equations to represent the relationships found in typical word problems is well known to be an area of difficulty for algebra students, Kieren (2007). According to Kieren, cited by Usman (2011), word problem situations not only continue to be used as a means for infusing algebraic objects with meaning but have also received increased emphasis in reform programs as vehicles for introducing students to algebra. Furthermore, she opined that, research in this area continues to provide evidence of students' preferences for arithmetic reasoning and their difficulties with the use of equations to solve word problems (e.g. Cortés, 1998; Swafford \& Langrall, 2000). Usman quoted Stacey and MacGregor (1999) as cited by Kieren, found that, at every stage of the process of solving problems algebraically, students were deflected from the algebraic path by reverting to thinking grounded in arithmetic problemsolving methods. Other researchers have concentrated on the difficulties associated with two major ways (syntactic and semantic) of translating equation from verbal data, (Kirshner et al, 1991; and Laborde, 1990).

Another aspect that contributes to students' difficulty in translating word problems into equations is language, (Kaput, 1987). To further buttress this claim, Stacey \& Macgregor (1993), cited by Usman (2011) stated that, an aspect of the natural language in which a mathematical relation is expressed may interfere with the process of translation into an algebraic representation. These aspects include complex syntax, the order of items of information, and the degree to which relations are made explicit.

On the other hand, Nathan and Koedinger (2004), cited by Kieren (2007), in a follow-up of their earlier study on students' performance on algebra word problems, algebra story problems and equations, found that algebra word problems are easier to solve than comparable questions presented in equations or word-equations. In their follow-up study, they established that students translate story problems into standard equation format only $5 \%$. They were challenged by the demands of comprehending the lettersymbolic form of the equation.

Considering the aforementioned issues rose in the literature on the students' algebraic learning difficulties with particular reference to the context of word problems, it would be beneficial and appropriate to conduct a study on the teachers' content knowledge in algebraic word problems

\section{Method}

\section{Design}

The design used for this study is a sequential mixed method, Creswell. It is a method of inquiry that comprises the techniques of collecting data quantitatively (test instrument) and qualitatively (content or document analysis) sequentially. The two methods are employed together consecutively because of the desire to give detail explanation and enhance the characteristics of the outcome, Collins, Onwuegbuzie, \& Sutton (2006). Furthermore, the two methods would enrich the data collected, which, consequently facilitate in the discovery of mistakes and delusions with respect to some English key words that 
represent mathematical operations. Additionally, the outcome from the two methods would also help to unearth the lapses of how these mathematical operations influence the construction of algebraic expressions, simple equations and their solution from algebraic word problems.

\section{Participants}

The participants were pre-service final year (Nigeria Certificate in Education, NCE) students from a Federal College of Education in the north western part of Nigeria. They consist of twenty males and ten females and have completed all courses that qualify them to teach at primary and junior/secondary school level.

\section{Instrument}

The test instrument was designed by the researcher to actualize the objective of the study. The test instrument consists of four components and are: (1) translating and classifying words/phrases into mathematical operations (addition, subtraction, multiplication, division, and equality); (2) translating word problems into algebraic expressions; (3) setting/constructing equations from word problems; (4) construction and solution of algebraic equations from word problems. The first three sections assess basic skills and knowledge of mathematical operations in equation construction, whereas the last part measures proficiency of students in applying these competences successfully/unsuccessfully in equation construction and its subsequent solution.

\section{Analysis}

The intent of this paper is to assess, investigate and analyze basic knowledge of mathematical operations (key words/phrases) that represent mathematical operations and how they were utilized in the construction of algebraic expressions, equations, construction and solution of equations from algebraic word problems. The data collected in quantitative and qualitative form were analyzed below.

\section{Quantitative Data Analysis}

The total number of pre-service teachers were engaged in this study was thirty, comprising twenty males $(67 \%)$ and ten females (33\%). They had completed a minimum of five out of six semesters required to complete the program. The reliability test for the data collected was Cronbach's Alpha of $0.56(\alpha=0.55)$, which is relatively sufficient.

Table 1.Descriptive Statistics of all Variables

\begin{tabular}{lcccccc}
\hline Variables & Mean & Median & Mode & Std. Deviation & Min & Max \\
\hline MTHOP* $^{*}$ & 4.19 & 2.84 & 1.5 & 3.02 & 0 & 10 \\
ALEXP* $^{*}$ & 3.9 & 4 & 4.5 & 1.22 & 1 & 5.5 \\
SMPLEQ* $^{*}$ & 2.7 & 2.75 & 3.5 & 1.84 & 0 & 7 \\
SLNALEQ $^{*}$ & 2.68 & 2 & 1 & 2.06 & 0 & 7 \\
TOTAL SCORE & 33.79 & 33 & 33 & 13.24 & 8.75 & 62 \\
\hline
\end{tabular}

MTHOP* = Mathematical operations; ALEXP* = Algebraic expressions'

SMPLEQ* = Simple Equations; SLNALEQ* = Solution of algebraic equations.

Total scores calculated in percentages (100\%).

Research question 1(a): Are pre-service teachers able to identify and classify selected words that represent mathematical operations? 
This research question investigates whether students are able to translate words/phases into mathematical operations of addition, subtraction, multiplication, division and equality. Students are expected to find appropriate match of mathematical operations for each word(s) or phrase(s). The vocabulary experience of the students is sufficient to allow fluent solution of the problem.

The descriptive statistics as shown in table 1 indicate a mean score of 4.19 out a maximum score obtainable of 10, with standard deviation of 3.02. This indicates high variability among the scores. The commonest score is 1.5, with minimum and maximum of 0 and 10 respectively. Overall, there are $16(53 \%)$ students who obtained a score below the mean, with $14(47 \%)$ students scoring above average. Using this as a bench mark, it can be inferred that students' performance in this task are relatively good.

Research question 2(a): Are pre-service teachers able to construct algebraic expression from word problems?

Section two of the test instrument assesses this research question. It examines students' ability to construct algebraic expressions from word problems (sentences/phrases). Computed result from the test instrument indicates a mean score of 3.90 out of maximum of 10 obtainable. The standard deviation of 1.22 is low, and this indicated a little variability among the variables. Other results from table 1 illustrated that, the most frequent score is 4.5, with minimum of 1 and maximum of 5.5. Frequency count from processed data found that $19(63 \%)$ students obtained a score that is above average; whereas, $11(37 \%)$ students were placed below the mean score. Inferences drawn from this shows a virtual satisfactory performance.

Research question 3(a): Are pre-service teachers able to construct simple equations from word problems?

Setting up a simple algebraic equation was the central feature of this research question. The mean score obtained in this task from table 1 is 2.70 , out of 10 points maximum available, with a standard deviation of 1.84. This standard deviation is low, indicating that the variables are clustered together. Other information from the table shows a minimum of 0 and maximum of 7 . Frequency tally shows that there are $15(50 \%)$ students that get a score of 2.70 or higher, whereas, $15(50 \%)$ students gained a score less than 2.7. Putting this information together from the descriptive statistics, it can be inferred that the pre service teachers were fairly able to construct simple equations from algebraic word problems.

Research question 4(a): Are pre-service teachers able to construct and solve equations from algebra word problems?

Aforementioned (research questions 1(a), 2(a), and 3(a)) appraised knowledge of mathematical operations, skills of constructing mathematical expressions and simple equations in isolated cases or situations respectively. It is expected that students would integrate these skills and facts in an attempt to answer this research question (4a). Results from table 1 shows a mean of 2.68 out of 10 obtainable, with standard deviation of 2.06. This standard deviation is relatively high, indicating a spread among the variables. Additional information deduced from table 1 revealed a minimum and maximum of 0 and 7 respectively. 11 (37\%) students are counted to have scored higher than 2.68 , while $19(63 \%)$ have obtained a score lower than the average. Clearly, there is a problem here. It can be inferred from the results that the students have not performed well in this non-isolated task. Integrating the concepts of variables and correct interpretations of mathematics operations were illusive. 


\section{Qualitative data analysis}

Qualitative data were generated by analyzing the pre-service teachers' manuscripts to further illuminate the quantitative result earlier discussed. Below is the detailed analysis of the qualitative components of the research questions.

Table 2.Descriptive statistics of Mathematical operations

\begin{tabular}{lcccc}
\hline Mathematical operations & Mean & Median & Mode & Std. Deviation \\
\hline Addition & 0.78 & 0.33 & 0.33 & 0.62 \\
Subtraction & 1.01 & 0.50 & 0.50 & 0.68 \\
Multiplication & 1.20 & 1.00 & 0.67 & 0.69 \\
Division & 0.58 & 0.33 & 0.00 & 0.55 \\
Equality & 0.61 & 0.25 & 0.00 & 0.72 \\
\hline
\end{tabular}

1b) How do the pre-service teachers able to identify and classify select words that represent mathematical operations.

Pre - service teachers performance on five mathematical operations that represent addition, subtraction, multiplication, division and equality were analyze qualitatively. Each mathematical operation was analyzed separately.

Addition: There are six phrases/words required to be translated into a mathematical operation of addition " + ". Total score possible in this task is two points. The mean score from table 2 for this variable is 0.78 with standard deviation of 0.62 , and a mode of 0.33 . Lower standard deviation indicates little spread among the variables. Two pre-service teachers (7\%) obtained a maximum score of 2 points, while the rest (93\%) achieved a score ranging from 0 to 1.65 points. Qualitative manuscripts analysis shows that many were struggling to recognize an appropriate word/phrase that represents a mathematical operation of addition. The word "sum" was the only word/phrase familiar with them. It could be inferred that a lack of experience and an inadequate knowledge of vocabulary representing mathematical operations of addition contributed to their poor performance in this task.

Subtraction: Four words/phrases are required to accomplish this task. From table 2, the maximum point obtainable is 2, with a mean of 1.01, standard deviation of 0.68 and a mode of 0.33 . Low standard deviation indicates that scores were not widely dispersed. Frequency-count shows that eight pre-service teachers obtained a maximum score of 2 points $(27 \%)$, whereas the rest of the sample (73\%) scored between 0 and 1.5 points. The qualitative analysis of the manuscript shows that they were unable to select and associate appropriate phrases/words representing subtraction with the mathematical operation of subtraction except for the minus.

Multiplication: There are three phrases/words in this task with the maximum score of 2 points obtainable. The mean score is 1.2 with a standard deviation of 0.69 and a mode of 0.67 . Eleven pre-service teachers (37\%) obtained a score of 2 points, i.e. full marks, while nineteen (63\%) scored between 0 and 1.34 points. Even though all the phrases/words were not unfamiliar, still, a greater part of the pre-service teachers were unable to recognize them as mathematical operations representing multiplication.

Division: Assigned items i.e. words/phrases in this task were six, with a maximum score obtainable of 2 points. Computed results (Table 2) from manuscripts shows a mean of 0.58 , standard deviation of 0.55 
and a mode of 0 . Minimal standard deviation indicated low variability among scores, i.e. scores are clustered together. One pre-service teacher (3\%) obtained a maximum score of 2 points, but the rest of the sample $29(97 \%)$ scored between 0 and 1.33. A further qualitative check of the manuscripts shows that a majority found it difficult to relate the words/phrases in the task with a mathematical operation of division. The words "quotient", "out of" had proven difficult for the pre-service teachers to handle.

Equality: Eight items were in this isolated task, with a highest score obtainable of 2 points. The mean mark for this task is 0.61 , standard deviation of 0.72 and mode of 0.72 . Low standard deviation indicates that level of dispersment among the variables is equivalently little. Three pre-service teachers $(10 \%)$ scored a maximum of 2 points, while $27(90 \%)$ had a score between 0 and 1.75 points. In fact, eleven among the twenty seven obtained a score of zero points, whereas, seven had a score of 0.25 points. Additional qualitative probing of their manuscripts indicates that unfamiliarity with mathematical operations representing equality serves as a big hurdle in this isolated task.

Summarizing this research question, mathematical operations of addition, multiplication and subtraction seems to attract relative fairly good performance. The bases of this conclusion was that their modes were not zero $(0.33,0.5$ and 0.67 respectively) compared with division and equality, that both had a mode of zero. In general, inexperience, and a lack of adequate vocabulary contributes greatly to the poor performance of pre-service teachers in these isolated tasks.

2b) How are pre-service teachers able to construct algebraic expressions from word problems?

Eight word problems are designed to investigate this research question, and are distributed as thus: one question, each for multiplication, addition, and division; two questions from mathematical operation of subtraction; and three questions are a combination of these mathematical operations. Average score in these tasks is 3.90 out of 10 points obtainable. Frequency count from pre-service teachers test manuscript indicated that eleven (37\%) score below 3.90, while nineteen (63\%) obtained a score above the average. Further qualitative analysis of the teachers test script shows that twenty $(87 \%)$ have answered the addition problem successfully, while multiplication recorded $100 \%$ success. However, word problems requiring the use of mathematical operations of subtraction and division witness a serious setback. In the subtraction problem, translating "less than" prove impossible as only two out of thirty solve it in reversed order. Example from the analyzed manuscript is: "5 less than $y$ " iswrittenas $5-y$. Most of them use "<" symbol in place of "- ". Mathematical operation involving division was also a hurdle for the pre-service teachers. Only seven out of thirty $(23 \%)$ were successful in the task. It was difficult to find the meaning for the word "quotient".

The last sets of questions in this section of constructing algebraic expressions consist of three questions. The first involves combination mathematical operations of addition and division. In this task, none of the pre-service teachers responded to the question successfully, but eight had solved it half-way through. An example of the pre-service teachers' manuscript: "ratio of 9 more than $t$ to $t$ " was writtenas" $9+t: t$ " . Translating "ratio" and "more than" to represent division and addition was a constraint, instead, they used ":" and ">" to signify division and addition respectively in the construction of algebraic expressions. The second question combines mathematical operations of addition and subtraction. In it, again, none of the pre-service teachers answered the task correctly, even though, nineteen out of thirty succeeded obtaining correct answers half-way through. Example from manuscript: 15 lessthanthesumofanumberand 7" was written as "15 $<n+7$ ". Impediments experienced by the preservice teachers in their attempt to solve the problem include the inability to translate "less than" to represent "- "subtraction symbol. Many use the symbol " $<$ " instead of "-" in their effort to construct the 
required algebraic expression. Similarly, the use of an addition symbol " + " to represent "more than" was proving difficult. A lot of them used the symbol " $>$ " instead of " + " to represent more than.

The third task requires the use of phrases "more than" and "in terms" to solve it. All the pre-service failed in this task. They couldn't find a relation between length and width using the phrase "more than", even though they were able to correctly use variables $l$ and $w$ to represent length and width respectively. Similarly, expressing one variable in terms of the other, for example "length in terms of width", was also not successful. Many pre-service teachers use " $>$ " symbol to represent "more than". Example $30>w$ was written to represent "length is 30 meters more than width". Some didn't even attempt the question.

To Summarize, using the symbols of mathematical operations of division, addition and subtraction as well as expressing one variable in terms of the other by means of "more than" in constructing algebraic expressions from word problems was proven to be difficult and insurmountable.

3b) How are pre-service teachers able to construct algebraic equations from word problems?

There are five items in this task required to answer the research question. The items were set to measure pre-service teachers' ability to construct simple equations from word problems in general. Hypothesize difficulties of the test items include but not limited to understanding and using variables appropriately, visualizing a right triangle and recognition of mathematical operations (addition, subtraction, multiplication, division and equality) in word problems. Results of the test scores from table 1 (quantitative component) indicated a mean of 2.7 and standard deviation of 1.84 out of maximum of 10 points. Fifteen $(50 \%)$ pre-service teachers are each categorized as above and below the average score. A qualitative analysis of the test manuscript was given below.

Many of the pre-service teachers were unable to use variables correctly to construct simple equations from word problems. Instead, they resorted in using numerical values (arithmetic approach) to solve the problems. Some of their approaches involved trial and error or what is sometimes called "guess and check". Specifically, establishing a relation between two numbers in which one is more than the other by a certain numerical value was proving impossible. Several sample problems from a test instrument were given below:

"A number is five more than the other and their sum is 17 "

"A number is 8 more than the other. The sum of four times the bigger and three times the smaller is 60".

"Share 99 pebbles between three members of a family in such a way that, whatever the first person get, the second person get four times that and the third person get five more than the second".

Although there are successful attempts among the pre-service teachers to establish the sum of two unknown numbers amounting to certain a numerical value using variables, but relating them again using "more than", "twice", "three", "is" was proven difficult, especially in ratio problems. Another setback exhibited by the pre-service teachers was their inability to establish a relationship between the sides of a right triangle (hypotenuse and two sides) using appropriate variables.

Summarizing, inappropriateness and failure in using variables as well as incorrect translations of mathematical operations had served as a hurdle for the pre-service teachers' abilities to construct simple equations. Some resorted to an arithmetic approach to solve problems instead of using variables to construct simple equations.

4b) How are pre-service teachers able to construct and solve algebraic equations completely? 
Five items are designed to appraise this research question. The intent is to assess pre-service teachers' capabilities to set-up and solve an algebraic equation from a word problem completely. Three items were conceived with hypothesize complexities such as use of variables for unknown numbers correctly; familiarizing and utilizing general form of consecutive numbers (odd/even); another item requires recognizing the structure of quadratic equations and finding its solution completely i.e. algebraic skills; and the last item involve visualizing a geometric word problem and making use of suitable mathematical operations to find a relationship between its dimensions. Quantitative test result Table I shows a mean score of 2.68, standard deviation of 2.06 and a mode of 1 from maximum score of 10.

The frequency count of the test manuscript indicated that eleven (37\%) pre-service teachers had scored marks that were above average, while nineteen $(63 \%)$ were placed below the mean. Qualitative analysis of the test manuscripts illustrated that, in the test item which requires finding consecutive numbers, only ten $(33 \%)$ out of thirty were successful in setting-up the equation using a variable and the general form of consecutive numbers and solving it correctly. The remaining twenty either used the arithmetic approach (i.e. guess and check) or didn't use any correct solution procedures completely. In another test item, using general form of consecutive even/odd number was illusive. Only three $(10 \%)$ out of thirty pre-service teachers made an attempt that was successful half-way through. In a similar way, there was only one successful attempt in recognizing a quadratic equation and solving it completely, however, there were four additional unsuccessful attempts made. They were able to recognize the quadratic equation but unable to solve it due to use of the wrong quadratic formula or factoring-method. In the last test item, there were relative success stories, as only eight out of thirty made unsuccessful attempts. They were unable to express length in terms of width, as well as relate numerical perimeter $24 m$ with the algebraic onep $=2 l+2 w$, i.e. $24=2 l+2 w$. Establishing a relationship between length and width using the phrase "more than" was a hurdle, i.e. "length is 3 meters more than the width".

Summarizing the findings from the last research question, it was clear that there were success stories among pre-service teachers in identifying and using the general form of consecutive numbers as well as odd/even from word problems, but that fate was not attainable by many. In a similar vein, solution of a word-quadratic equation was proven to be difficult, as well as establishing a relation between numerical and algebraic values of a perimeter using the phrase "more than".

\section{Conclusion, Discussion and Recommendation}

The overall objective of the study is to assess senior/junior secondary school pre-service teachers' content knowledge of algebraic word problems in a senior/junior secondary mathematics curriculum. Specifically, how do the complementary qualitative results help in illuminating the quantitative outcome? Both quantitative and qualitative analysis of the results revealed the following.

Weak knowledge, recognition and understanding of mathematical operations (addition, subtraction, multiplication, division and equality). In these isolated instances, there was a profound failure in the identification and usage of mathematical operations of division and equality by the pre-service teachers, even though they were able to demonstrate a little skill in that respect for addition, subtraction and multiplication. This vulnerability was clearly reflected in other sections of the test instrument (construction of algebraic expressions and equations) that requires application of knowledge of these mathematical operations. 
There was an inadequate comprehension of the general structure of consecutive numbers as well as general structure of consecutive even/odd numbers. Writing the structure of consecutive numbers as well as consecutive even/odd numbers using appropriate variables was inaccessible. There was an absence of algebraic skills (recognizing word-quadratic equation and using appropriate solution process either by factoring, completing the square or formula). Furthermore, they have demonstrated inability to visualize geometric diagrams (right triangle/rectangle) as well as an improper use of variables to name their unknown sides.

The educational implications of this study are that the algebraic processes taught at college level may not provide the pre-service teachers with thorough knowledge of mathematical operations, the techniques of equation construction, and the appropriate use of variables as well as visualization. The reason postulated was that mathematics educators at the college level assume that pre-service teachers have acquired such type of skills and facts from senior/junior secondary schools.In a related development, lack of conceptualization of general structure of numbers (consecutive, even/odd) that was displayed by the pre-service teachers was also ignored at the college level, even though, courses dealing with that were taken by the pre-service teachers. Again, it is generally assumed that, pre-service teachers have that knowledge, but alas, it wasn't the case.

It would be in the interest of the mathematics education community in Nigeria to imbibe and help preservice teachers of mathematics develop junior/senior secondary school mathematics curriculum. They shouldn't assume that pre-service teachers have that knowledge, rather, they should be formally taught the content of the senior/junior secondary school mathematics curriculum. The benefit of formally teaching junior/senior secondary school mathematics curriculum is that, the pre-service teachers stand to optimize their mathematics content knowledge as well as their pedagogical content knowledge.

\section{Reference}

Afe, J. O. (2006). Reflections on Becoming a Teacher and the Challenges of Teacher Education.Faculty of Education, University of Benin, Benin City, Nigeria. Inaugural Lecture series 64

Akinbote, O. (2007). Problems for Teacher Education for Primary Schools in Nigeria: Beyond Curriculum Design and Implementation. Essays in Education, 22.

Ambrose, R. (2004). Integrating change in prospective elementary school teachers' orientations to mathematics teaching by building on beliefs.Journal of Mathematics Teacher Education, 7(2), 91 - 119.

Angus, D. L. (2001).Professionalism and the public good: A brief history of teacher certification. Washington, D.C: Thomas Fordham Foundation.

Ball, D. L., Lubienski, S., \&Mewborn, D.S. (2001). Research on teaching mathematics: The unsolved problem of teachers' mathematical knowledge. In V. Richardson (Ed), Handbook of research on teaching (4 ${ }^{\text {th }}$ ed., pp. 433 - 456). Washington, D.C.: American Educational Research Association.

Borko, H., et al (1992). Learning to teach hard mathematics: Do novice teachers and their instructors give up too easily? Journal for Research in Mathematics Education, 23, $194-222$.

Cortés, A. (1998). Implicit cognitive work in putting word problems into equation form.In A. Olivier \& K. Newstead (Eds.), Proceedings of the $22^{\text {nd }}$ Conference of the International Group for the Psychology of Mathematics Education (Vol. 2, pp. 208-216). Stellenbosch, South Africa: PME.

Ejima, O. S. (2012). Teacher Professional Development in the 21 $1^{\text {st }}$ Century Nigeria: The Journey, the potholes and the patches. Global Voice of Educators, 1(1).

Federal Government of Nigeria (2004).National Policy on Education. Lagos: NERDC.

Federal Ministry of Education, Senior Secondary Education Curriculum: Mathematics for SS 1 - 3. Nigerian Educational Research and Development Council (NERDC).

Hiebert, J., et al (2005). Mathematics teaching in the United States today and tomorrow: results from the TIMMS 1999 video study. Educational Evaluation and Policy Analysis, 27(2), $111-132$.

Hill, et al. (2007).Assessing Teachers' Mathematical Knowledge: What Knowledge Matters and What Evidence Counts.In Frank K. Lester, Jr. (Ed.), Second Handbook of Research on Mathematics Teaching and Learning. Greenwich, CT: Information Age Publishing. 
Hill, H., \& Ball, D. (2004). Learning mathematics for teaching: Results from California's mathematics professional development institute. Journal for Research in Mathematics Education, 35(5), 330 - 351. Hillsdale: Erlbaum.

Ibidapo-Obe, O. (2007). The challenge of teacher education in Nigeria: The University of Lagos Experience. Paper presented at the Second Regional Research Seminar for Africa, organized by the UNESCO forum on Higher Education, Research and Knowledge in Accra, Ghana, 22 - 24March 2007.

Jekayinfa, A.A. (n.d). Development of Teacher education in Nigeria.

Kaput, J. (1987). Towards a theory of symbol use in mathematics (C. Janvier Ed), Problems of representationin the teaching and learning of mathematics (pp. 159 - 195).

Kieran, Carolyn (2007). Learning and Teaching Algebra at the Middle School through CollegeLevels: Building Meaning for Symbols and Their Manipulation. In Frank K. Lester, Jr. (Ed.), Second Handbook of Research on Mathematics Teaching and Learning.Greenwich, CT: Information Age Publishing.

Kirshner, D., Awtry, Y., McDonald, J., \& Gray, E. (1991).The cognitive caricature of mathematical thinking: The case of the students and professors problem. Paper presented at the Thirteenth AnnualConference of the North American Chapter of the international Group for the Psychology of Mathematics Education, Blacksburg, Va.

Koedinger, K.R., \& Nathan, M.J. (2004). The real story behind story problems: Effects of representations on quantitative reasoning. Journal of the Learning Sciences, 13, 129-164.

Laborde, C. (1990). Language and Mathematics (P. Nesher\& J. Kilpatrick Ed), Mathematics and cognition (pp. 53 - 69). Cambridge: Cambridge University Press.

Ma, L. (1999).Knowing and teaching elementary mathematics: Teachers' understanding of fundamental mathematics in China and the United States. Mahwah, NJ: Erlbaum.

Mohr, M. (2006).Mathematics knowledge for teaching.School $\backslash$ Science and Mathematics, 106(6), 219 - 220.

National Commission for Colleges of Education (2012).Nigeria Certificate in Education Minimum Standards for Sciences. Abuja.

Ogunrinade, D. O. A. (2013). Philosophy of Music Education in Nigeria: Content Analysis of Music Curriculumfor Nigeria Certificate in Education (NCE). Journal of Philosophy, Culture and Religion, 1.

Okemakinde, T., Adewuyi, J.O., Alabi, C. O. (2013).The Place of Teacher in NationalDevelopment in Nigeria.European Journal of Humanities and Social Sciences, 19(1).

Osuji, S. N. (2009). Teacher Education Curriculum in Nigeria in the perspectives of Lofelong Education. The Journal of International Social Research 2(8).

Oyekan, S. O. (2006). Foundations of Teacher Education. Ibadan. Ben Quality Prints.

Oyeleke, O., Akinyeye, C. O., Opeloye, B. A., (2013). A Critique of Teaching Profession and Teacher Education in Nigeria. International Journal of Humanities and Social Science, Vol. 3 No. 5;(pp. 267 - 273).

Schmidt, S., \& Bednarz, N. (1997).Raisonnements arithmétiques et algébriques dans un contexte de résolution de problèmes: Difficultés rencontrées par les futurs enseignants [Arithmetic and algebraicreasoning in a problem-solvingcontext: Difficultiesencountered by pre-service teachers] Educational Studies in Mathematics, 32, 127-155.

Schmidt, S., \& Bednarz, N. (1997).Raisonnements arithmétiques et algébriques dans un contexte de résolution de problèmes: Difficultés rencontrées par les futurs enseignants [Arithmetic and algebraicreasoning in a problem-solvingcontext: Difficultiesencountered by pre-service teachers] Educational Studies in Mathematics, 32, 127-155.

Schommer-Aikins, M., Duell, O., \& Hutter, R. (2005).Epistemological beliefs, mathematics problem solving beliefs, and academic performance of middle school students.The Elementary School Journal, 105(3), 289-303.

Shulman, L.S. (1986). Those Who Understand: Knowledge Growth in Teaching. Educational Researcher, 15(2), (4-14).

Simon, M. (1993).Prospective elementary teachers' knowledge of division.Journal for Research in Mathematics Education, 24(3), 233 254.

Stacey, K., \& MacGregor, M. (1999).Learning the algebraic method of solving problems.Journal of Mathematical Behavior, 18, 149167

Stacey, K., \& MacGregor, M. (1999).Learning the algebraic method of solving problems.Journal of Mathematical Behavior, 18, 149-167.

Swafford, J. O., \& Langrall, C. W. (2000). Grade 6 students' preinstructional use of equations to describe and represent problem situations. Journal for Research in Mathematics Education, 31, 89-112.

Swafford, J. O., \& Langrall, C. W. (2000). Grade 6 students' preinstructional use of equations to describe and represent problem situations. Journal for Research in Mathematics Education, 31, 89-112.

Tirosh, D., \&Graeber, A. O., (1990).Evoking cognitive conflict to explore preservice teachers' thinking about division.Journal for Research in Mathematics Education, 21(2), 98 - 108.

Tom-Lawyer, O. (2014). An Evaluation of the English Language Curriculum of the Nigeria Certificate in Education: A case study of a College of Education. Open Journal of Social Sciences, 2, 69-79.

Usman, A. I., (2011). Analysis of Diagram Construction in Applied Calculus Problem Solving.In the proceedings of Canada International Conference on Education, Toronto, Canada.

Van Dooren, W., Verschaffel, L., \&Onghena, P. (2002).The impact of preservice teachers' content knowledge on their evaluation of students' strategies for solving arithmetic and algebra word problems.Journal for Research in Mathematics Education, 33, 319351. 
Van Dooren, W., Verschaffel, L., \&Onghena, P. (2003). Pre-service teachers' preferred strategies for solving arithmetic and algebra word problems. Journal of Mathematics Teacher Education, 6, 27-52.

Walshaw, M. (2012).Teacher knowledge as fundamental to effective teaching practice. Journal of Mathematics Teacher Education.15: $181-185$.

Zazkis, R., \&Liljedahl, P. (2002). Generalization of patterns: The tension between algebraic thinking and algebraic notation. Educational Studies in Mathematics, 49, 379-402.

Zazkis, R., \&Liljedahl, P. (2002). Generalization of patterns: The tension between algebraic thinking and algebraic notation. Educational Studies in Mathematics, 49, 379-402.

Zerpa, C., Kajander, A., Barneveld, C. V. (2009). Factors that Impact Pre-service Teachers' growth in conceptualMathematical knowledge during a Mathematics Method Course.InternationalElectronic Journal of Mathematics Education, 4(2). 